\title{
The C-terminal fragment of the immunoproteasome PA28S (Reg alpha) as an early diagnosis and tumor-relapse biomarker: evidence from mass spectrometry profiling
}

\author{
Rémi Longuespée - Charlotte Boyon - Céline Castellier • Amélie Jacquet • \\ Annie Desmons · Olivier Kerdraon - Denis Vinatier - Isabelle Fournier • \\ Robert Day $\cdot$ Michel Salzet
}

Accepted: 30 March 2012/Published online: 25 April 2012

(C) Springer-Verlag 2012

\begin{abstract}
This study reports on the C-terminal fragment of the 11S proteasome activator complex (PA28 or Reg alpha), a novel ovarian-specific biomarker of early and late stages of ovarian cancer (OVC) relapse, in patient biopsies after chemotherapy. A total of 179 tissue samples were analyzed: 8 stage I, 55 stage III-IV, 10 relapsed serous carcinomas, 25 mucinous carcinomas and 12 borderline and 68 benign ovarian tissue samples. This fragment was detected by MALDI mass spectrometry profiling in conjunction with a novel extraction method using hexafluoroisopropanol (1,1,1,3,3,3-hexafluoro-2-propanol; HFIP) solvents for protein solubilization and by immunohistochemistry using a specific antibody directed against the C-terminal fragment of PA28. Due to its specific cellular localization, this fragment is a suitable candidate for early OVC diagnosis, patient prognosis and follow-up during therapy and discriminating borderline cancers. Statistical analyses performed for this marker at different OVC stages
\end{abstract}

R. Longuespée - C. Boyon - C. Castellier - A. Jacquet . A. Desmons · D. Vinatier · I. Fournier · M. Salzet ( $₫)$ Laboratoire de Spectrométrie de Masse Biologique Fondamentale et Appliquée, Université Nord de France, EA 4550, Université de Lille 1, Cité Scientifique, 59650 Villeneuve D’Ascq, France

e-mail: Michel.salzet@univ-lille1.fr

R. Longuespée · R. Day

Institut de Pharmacologie de Sherbrooke, Université de Sherbrooke, Sherbrooke, QC J1H 5N4, Canada

C. Boyon - C. Castellier - A. Jacquet $\cdot$ D. Vinatier Hôpital Jeanne de Flandre, Service de Chirurgie Gynécologique, CHRU Lille, 59037 Lille Cedex, France

O. Kerdraon

Laboratoire d'Anatomie et de Cytologie Pathologiques, CHU Lille, 59037 Lille Cedex, France reflect a prevalence of $77.66 \pm 8.77 \%$ (with a correlation coefficient value $p<0.001$ of 0.601 between OVC and benign tissue). This marker presents a prevalence of $88 \%$ in the case of tumor relapse and is detected at $80.5 \%$ in stage I and $81.25 \% \pm 1.06$ in stage III-IV of OVC. The correlation value for the different OVC stages is $p<0.001$ of 0.998. Taken together, this report constitutes the first evidence of a novel OVC-specific marker.

Keywords Ovarian cancer - MALDI imaging · Biomarker · Relapse · Diagnostic · Mass spectrometry

\section{Introduction}

Since the concept of directly identifying molecules on tissues using MALDI ion sources was proposed at the end of the 1990s (Caprioli et al. 1997), MALDI imaging mass spectrometry has been used in many clinical applications (Cornett et al. 2006; El Ayed et al. 2010; Lemaire et al. 2006a, b; Pevsner et al. 2009; Schwamborn et al. 2007; Schwartz et al. 2004; Seeley and Caprioli 2008). A decade of developments in instrumentation and chemistry has been required to achieve optimal extraction, detection, and spatial resolution when mapping compounds at the tissue level (Franck et al. 2009a, b; Lemaire et al. 2006a, b; 2007a; van Remoortere et al. 2010). These developments, combined with using the appropriate data-processing tools, gave rise to the discovery of biomarkers for diverse pathologies (Bonnel et al. 2011; Djidja et al. 2010; McCombie et al. 2005; Stauber et al. 2008), of which cancer is the most studied. MALDI mass spectrometry imaging (MALDI-MSI) technology makes it possible to study the molecular profiles of the benign and malignant portions of a solid tumor. This technique is particularly 
interesting for screening biomarkers in stage I cancer biopsies, a stage when the disease is still treatable and the 5 -year survival rate for managed patients is yet high.

In the USA, ovarian cancer (OVC) is the sixth most prevalent cancer among women and the second most prevalent gynecologic cancer (after endometrial cancer). A total of 21,550 new cases and 14,600 deaths were reported in 2009 (Khalil et al. 2010). Cancer antigen 125 (CA-125: MUC16) is the most commonly used of the known biomarkers. CA-125 has a sensitivity of $80 \%$ and a specificity of $97 \%$ in epithelial cancers (stage III or IV). However, its sensitivity is approximately $30 \%$ in stage I cancers because it is associated with several physiological phenomena and is also detectable in benign circumstances (Lambaudie et al. 2006). Therefore, CA-125 is useful for monitoring disease progression, but it cannot be used as a biomarker to screen for early-stage disease in large cohorts (Lambaudie et al. 2006).

Our group has previously found that the C-terminal fragment of the 11S proteasome activator (PA28, Reg alpha) was specifically found in cancerous ovarian biopsies and not in benign tissues (Lemaire et al. 2005; 2007b) (Table 1). Using 25 ovarian carcinomas (stage III and IV) and 23 benign ovarian tissues analyzed by MALDI-TOF-MS, this new biomarker was detected with a high prevalence $(80 \%)$ and has been fully characterized using MALDI-MS and nanoESI trypsin peptides profiling. The full identification was performed by nano-ESI-QTOF in MS/MS mode. This marker has an $\mathrm{m} / \mathrm{z}$ ratio of 9,744 and corresponds to 84 amino acid residues from the $11 \mathrm{~S}$ proteasome activator complex

Table 1 This cohort was established 6 years ago through collaboration between FABMS and Hospital Jeanne de Flandre, CHRU Lille and consisted of 179 specimens

\begin{tabular}{llll}
\hline $\begin{array}{l}\text { Pathology } \\
\text { type }\end{array}$ & $\begin{array}{l}\text { MALDI-MSI, } \\
\text { identification, } \\
\text { validation }\end{array}$ & $\begin{array}{l}\text { MALDI } \\
\text { profiling }\end{array}$ & Immunohistochemistry \\
\hline
\end{tabular}

Serous cancer

\begin{tabular}{|c|c|c|c|}
\hline Stage I & 5 & 8 & 8 \\
\hline Stage III-IV & 35 & $55^{*}$ & $28 * *$ \\
\hline Relapse & 5 & 10 & 5 \\
\hline \multicolumn{4}{|c|}{ Mucinous cancer } \\
\hline Stage III-IV & 10 & 25 & 15 \\
\hline Borderline & 10 & 12 & 10 \\
\hline Benign & 43 & $68 *$ & $19 * *$ \\
\hline
\end{tabular}

The sample collection was performed with institutional review board approval (CCP Nord Ouest IV, CP 10/05 then CP 10/12). All of the human tissues were resected by a surgeon affiliated with FABMS, preserved immediately in isopentane, placed in nitrogen, and stored at $-80{ }^{\circ} \mathrm{C}$ until analysis. The data from this cohort have been previously published (El Ayed et al. 2010; Franck et al. 2009a; Lemaire et al. 2005, 2007b; Stauber et al. 2006)

* 25 OVC versus 23 benign were identified previously named PA28 or Reg alpha. This marker was validated using MALDI imaging, by classical immunocytochemistry with an antibody against the $\mathrm{C}$-terminal portion of the protein, by specific MALDI with an anti-Reg alpha-tagged antibody and by Western blot analyses. The results confirmed the epithelial localization of this fragment, with a nuclear localization in benign epithelial cells and a cytoplasmic localization in malignant cells (Lemaire et al. 2005, 2007b; Stauber et al. 2006). More recently, 20 ovarian carcinomas (stages I, III and IV) and 10 borderline and 20 benign ovarian tissue samples were directly analyzed by automatic profiling mass spectrometry subjected to hierarchical clustering, using unsupervised principal component analysis and characterized using a tissue bottom-up strategy after on-tissue digestion and shotgun sequencing by nano-LC-IT-MS in MS/MS mode (El Ayed et al. 2010; Franck et al. 2010). In all of the cases, the C-terminal fragment of Reg alpha was detected and identified. We also confirmed that this peptide is a marker for the immunosuppressive events that occur during disease progression (Franck et al. 2009a; Longuespée et al. 2012).

Based on previous data showing that the Reg-alpha C-terminal fragment can be detected in the late stages (III-IV) of OVC and can discriminate among borderline tissues, we investigated the properties of this marker after chemotherapy for early-stage OVC. Advanced OVC treatment involves explorative celioscopic surgery followed by neoadjuvant treatment with paclitaxel and platinum or with carboplatin and paclitaxel (Lhomme et al. 2009) if carcinosis is visible during the explorative celioscopic surgery. Radical surgery is then performed if the chemotherapeutic treatment efficiently removes the entire genital tract. The 5-year survival rate remains poor at approximately $40 \%$ (Kehoe 2008; Tanner et al. 2012). The responders will relapse approximately 18 months after completing first-line therapy and will require further systemic therapy. The median survival of patients with recurrent OVC ranges from 12 to 24 months. The traditional clinical measures of relapse include disease progression (usually defined as a $25 \%$ or greater increase in tumor size), appearance of new lesions and death. In this context, it is important to have an easily executed, highly reliable procedure. We investigated the expression of our proposed marker in the cancerous regions of interest by comparing the molecular profiles of small cancerous tissue areas with those of benign areas from the same tissue section. Extracting the marker compounds from the regions of interest was challenging due to the small size of the cancerous or benign regions.

To access a small polar protein with an $\mathrm{m} / \mathrm{z}$ ratio of 9,744 , we previously developed a sample preparation method using hexafluoroisopropanol (1,1,1,3,3,3-hexafluoro-2-propanol; HFIP) solvent, which is optimal for polar or high-mass proteins, for protein solubilization (El 
Ayed et al. 2010; Franck et al. 2010). This technique has been preferred over classical methods (Redeby et al. 2004, 2006). Using this method, the Reg-alpha C-terminal fragment was detected in early-stage (stage I) serous OVC and in patients who present with OVC recurrence after chemotherapy. Therefore, the fragment can be considered a marker for tumor relapse. This work provides evidence that Reg alpha is a novel OVC biomarker and that MALDI-MSI tissue profiling is useful for early-stage OVC diagnosis and for evaluating the prognosis of OVC patients.

\section{Materials and methods}

\section{Materials}

Sinapinic acid (SA), trifluoroacetic acid (TFA), and HFIP were obtained from Sigma-Aldrich and used without further purification. Water, acetonitrile, methanol, ethanol, and acetone were provided by Biosolve. The anti-Regalpha polyclonal antibodies were purchased from Invitrogen. The secondary antibodies for fluorescence microscopy were provided by Jackson, and the mounting medium was obtained from Vectashield.

\section{Samples}

The tissues (179 samples, Table 1) were obtained with informed consent and institutional review board approval (CCP Nord Ouest IV, CP 10/12) from patients undergoing ovarian tumor resection at the Hospital Jeanne de Flandre. The patient information collected included age, treatment received before and after surgery, extent of surgery, current status (i.e., alive, alive with progressive disease, deceased, and cause of death), and survival from the time of the original pathological diagnosis. The samples were collected during the surgery, immediately frozen in $-50{ }^{\circ} \mathrm{C}$ isopentane, and stored at $-80{ }^{\circ} \mathrm{C}$ until analysis. Typically, $10-\mu \mathrm{m}$ sections were cut using a cryostat and thaw-mounted on flat electrically conductive sample slices (indium tin oxide). The histopathological diagnoses were performed by a pathologist (O.K.) who was blinded to the original clinical diagnosis using subsequent H\&E-stained sections.

\section{Tissue preparation}

The frozen $10-\mu \mathrm{m}$ ovarian sections were sliced on a cryostat and immediately transferred onto conductive indium tin oxide (ITO) glass (Bruker Daltonics, Wissenbourg, France). The tissues were dried using a desiccator, and the sections were washed for $1 \mathrm{~min}$ in an acetone solution, $15 \mathrm{~s}$ in a $70 \%$ ethanol solution, $15 \mathrm{~s}$ in a $95 \%$ ethanol solution, and $1 \mathrm{~min}$ in chloroform.

\section{Microscopy methods}

Hematoxylin-eosin-safranin staining

For the hematoxylin-eosin-safranin (HES) staining, the sections were heated for $5 \mathrm{~min}$ and stained with hematoxylin for $3 \mathrm{~min}$. The sections were rinsed with water prior to being bathed twice in a solution containing $156 \mathrm{~mL}$ of $95 \% \mathrm{EtOH}$, $44 \mathrm{~mL}$ of $\mathrm{H}_{2} \mathrm{O}$ and $80 \mu \mathrm{L}$ of $\mathrm{HCl}$. The sections were rinsed in $\mathrm{H}_{2} \mathrm{O}$, a solution of $0.48 \mathrm{~mL}$ of $35 \% \mathrm{NH}_{4} \mathrm{OH}$ and $200 \mathrm{~mL}$ of $\mathrm{H}_{2} \mathrm{O}$, and $\mathrm{H}_{2} \mathrm{O}$ for an additional 5 min each. The sections were then rinsed in $80 \%$ ethanol, stained with eosin for $10 \mathrm{~s}$, and washed twice with $95 \%$ ethanol and twice in $100 \%$ ethanol. Finally, the sections were stained with safranin $(10 \mathrm{~g} / \mathrm{L}$ in $100 \% \mathrm{EtOH})$ for $6 \mathrm{~min}$ and washed twice in $100 \% \mathrm{EtOH}$ and once in xylene for $1 \mathrm{~min}$.

\section{Fluorescence microscopy}

The sectioned tissues were pre-incubated with a PBS buffer containing $1 \%$ BSA, $0.05 \%$ Triton, $1 \%$ ovalbumin, and $1 \%$ normal goat serum (NGS) for $30 \mathrm{~min}$ and then incubated with a specific rabbit polyclonal anti-C-terminal Reg-alpha antibody that was diluted to $1 / 100$ with a PBS solution containing $1 \%$ BSA, $0.05 \%$ Triton X-100, $1 \%$ NGS, and $1 \%$ ovalbumin (AB solution). A total of $500 \mu \mathrm{L}$ of the antibody solution was added to each tissue section, and the sections were incubated overnight at $4{ }^{\circ} \mathrm{C}$. After washing three times with PBS, the samples were incubated for $1 \mathrm{~h}$ at room temperature with goat anti-rabbit goat antibody (Invitrogen) conjugated to Alexa Fluor 488 (1:2,000 in the AB solution), rinsed with PBS, and mounted with Glycergel (Sigma Life Science, USA). The samples without primary antibody were used as negative controls. The slides were maintained in the dark at $4{ }^{\circ} \mathrm{C}$ until observation and analysis with an inverted Leica DM IRE 2 microscope. The light exposition was $100 \mathrm{~ms}$.

\section{Immunohistochemistry}

The immunohistochemistry (IHC) was performed on paraffin-embedded ovarian tissues using a standard peroxidase-based staining method. The paraffin-embedded 4- $\mu \mathrm{m}$ tissue sections were cut on a microtome and dried for $12 \mathrm{~h}$ at $60{ }^{\circ} \mathrm{C}$, dewaxed with $100 \%$ xylene for $5 \mathrm{~min}$, and rehydrated in brief successive baths of $100 \%$ alcohol, $95 \%$ alcohol, and distilled water. The tissue sections were stored in distilled water until the following steps were performed. The endogenous peroxidase activity was quenched with $10 \% \mathrm{H}_{2} \mathrm{O}_{2}$ for $5 \mathrm{~min}$. The tissue sections were incubated with the primary anti-Reg alpha C-term antibody (Zymed Laboratories, Invitrogen, ref. 3-2400) at a dilution of $1 / 50$ in TBS $(50 \mathrm{mM}, \mathrm{pH} 7.4)$ for $1 \mathrm{~h}$ at room temperature. The tissue sections were washed with TBS 
and successively incubated with the secondary antibody (biotin-streptavidin peroxidase, horseradish peroxidase (HRP) conjugate) and the chromogen (3,3'-diaminobenzidine) following the manufacturer's protocol (streptavidinHRP, Southern Biotechnology and Associates, Inc.). The nuclei were counterstained with hematoxylin.

\section{Mass spectroscopy methods}

\section{HFIP extraction method}

To extract compounds from the small-area stage I tissue biopsies, a hydrophobic solvent was used following the procedure previously described by our group (Franck et al. 2010; van Remoortere et al. 2010). A total of $10 \mathrm{mg}$ of SA was dissolved in $1 \mathrm{~mL}$ of HFIP. A total of $3 \mu \mathrm{L}$ of the solution was manually dropped onto the region of interest in $60.5-\mu \mathrm{L}$ droplets. After this deposition, $3 \mu \mathrm{L}$ of $10 \mathrm{mg} / \mathrm{mL}$ SA in $1 \%$ ACN/aqueous TFA (7:3) was added.

The same procedure was used to extract compounds from the large-area stage III and IV tissue biopsies, except that a total of $10 \mu \mathrm{L}$ of SA in HFIP was dropped onto the tissue section in $52-\mu \mathrm{L}$ droplets. A total of $10 \mu \mathrm{L}$ of SA in $0.1 \%$ ACN/TFA 7:3 was added.

Tissue profiling using MALDI mass spectrometry

The molecular profiling was performed on an UltraFlex II MALDI-TOF/TOF instrument (Bruker Daltonics, Bremen, Germany) equipped with a micro-channel plate (MCP) detector. The instrument was equipped with a Smartbeam ${ }^{\text {TM }}$ laser and controlled by FlexControl 3.0 (Build 158) software (Bruker Daltonics, Bremen, Germany). For the stage I tissue biopsies, the raw spectra were compared using the FlexAnalysis 3.0 software (Bruker Daltonics, Bremen, Germany). The spectra from the stage III and stage IV biopsies were processed with the FlexAnalysis 3.0 software (Bruker Daltonics, Bremen, Germany) using the convex hull baseline subtraction method. The spectra were recorded in positive ion, linear time-of-flight mode. For these experiments, the laser offset was typically set to $30 \%$, the laser range was set to $20 \%$, the laser fluence was set to $50 \%$, and the laser focus was set to small.

\section{Results}

Using MALDI-MSI followed by classical proteomic methods, we previously identified from $25 \mathrm{OVC}$ (stage III and IV) and 23 benign ovarian tissues, the C-terminal Reg-alpha fragment marker (Table 1). This marker has been validated by Western blot (9 OVC (stage III and IV) versus 16 benign ovarian tissues) (Lemaire et al. 2007b). A new strategy to investigate this marker at different OVC stages and grades has been developed (Table 1). We investigated the expression of this marker in the cancerous regions of interest by comparing the molecular profiles of small cancerous tissue areas with normal areas from the same tissue section. Extracting marker compounds in the regions of interest was challenging due to the small size of the cancerous and benign regions. Therefore, we developed a procedure that improved compound extraction from small regions of interest by using the HFIP extraction buffer (El Ayed et al. 2010; Franck et al. 2010). HFIP is applied directly to the tissue to improve polar protein extraction. The mass spectra of the classical MALDI mass spectrometry imaging and the profiling procedure using only SA without HFIP on the tissue extractions demonstrate that the C-terminal Reg-alpha fragment with an $\mathrm{m} / \mathrm{z}$ ratio of 9,744 is either not detected or not clearly distinguishable from the chemical spectral background (Fig. 1). The spectral differences observed when detecting this fragment in a 5-mm cancerous region from stage I OVC serous tissue (Fig. 2) using the HFIP extraction (Fig. 1a) or classical matrix deposition procedure (Fig. 1b) confirmed this hypothesis. The ion at 9,744 can be easily detected in small tissue fragments using the HFIP procedure (Fig. 1a), whereas only a small SA peak is detected without HFIP (Fig. 1b).

\section{The C-terminal Reg-alpha fragment is a specific OVC-diagnosis marker}

We first validated our on-tissue extraction procedure using the late-stage OVC samples. Under these conditions, 30 stage IIIc and IV serous OVCs versus 45 benign were analyzed by MALDI-MS profiling after on-tissue extraction (Fig. 2a). The mass spectra focused on the ion at 9,744, which corresponds to the C-terminal Reg-alpha fragment and was present in all of the ten stage IIIc or IV serous adenocarcinomas (ADK, Fig. 2a). We validated these results on 12 patients using immunohistochemistry (IHC) (Figs. 3, 4). Among these 12 patients, 7 OVC were diagnosed ( 2 of which were on the same specimen or on the same cut) and 2 demonstrate a well-differentiated morphology (one benign or typically benign and malignant morphologies). Moreover, among the seven ovarian cancers, there was an endometrioid carcinoma of which a large area of the specimen was found to be an undifferentiated carcinoma. The two sections amount to two different ovarian cancers on the same ovary. A total of 15 samples were tested: 8 malignant and 7 benign (Figs. 3, 4). The signal was consistently balanced, with a cytoplasmic localization in the cancer cases $(87.5 \%$ were balanced, $n=7 / 8$ with cytoplasmic labeling specifically in the endometrioid carcinomas) and a predominantly nuclear localization in the benign tumors (96\% nuclear labeling) (Table 2). 
Fig. 1 The spectral differences observed between the classical and HFIP protein extraction methods from small tissue sections. a The profiling spectrum obtained from a 4-mm cancerous region of a stage I serous cancerous tissue using the HFIP procedure; $\mathbf{b}$ the spectrum generated with the classical drop-of-SA method. With the classical drop method, the C-terminal Reg-alpha fragment is not clearly distinguishable from the background. In contrast, this fragment is readily apparent using the HFIP procedure
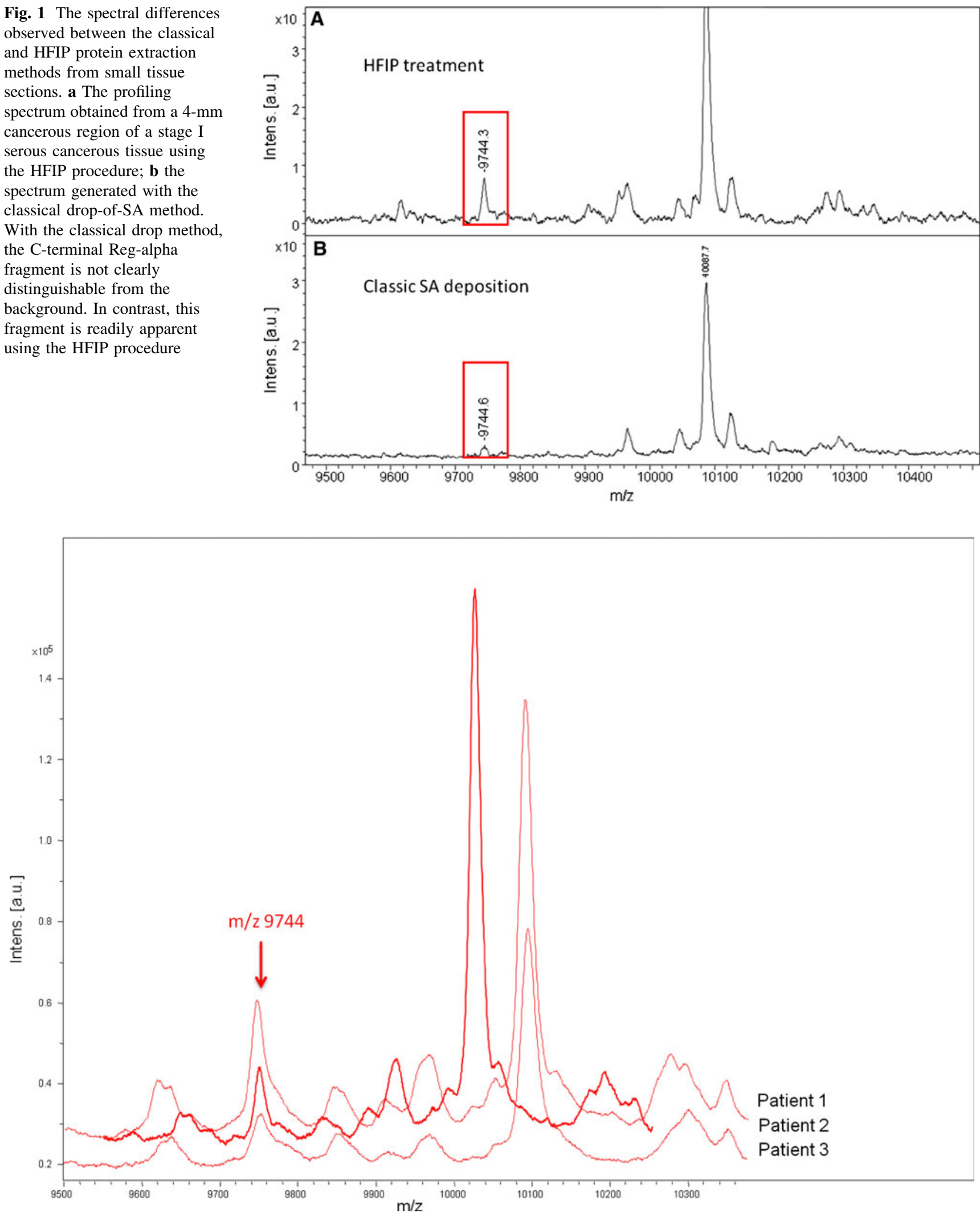

Fig. 2 MALDI-MS spectra of the HFIP extracts from the carcinoma regions of three different stage III-IV patients. The ion with an m/z ratio of 9,774 corresponds to the C-terminal Reg-alpha fragment, which is found in each patient and indicated by an arrow 


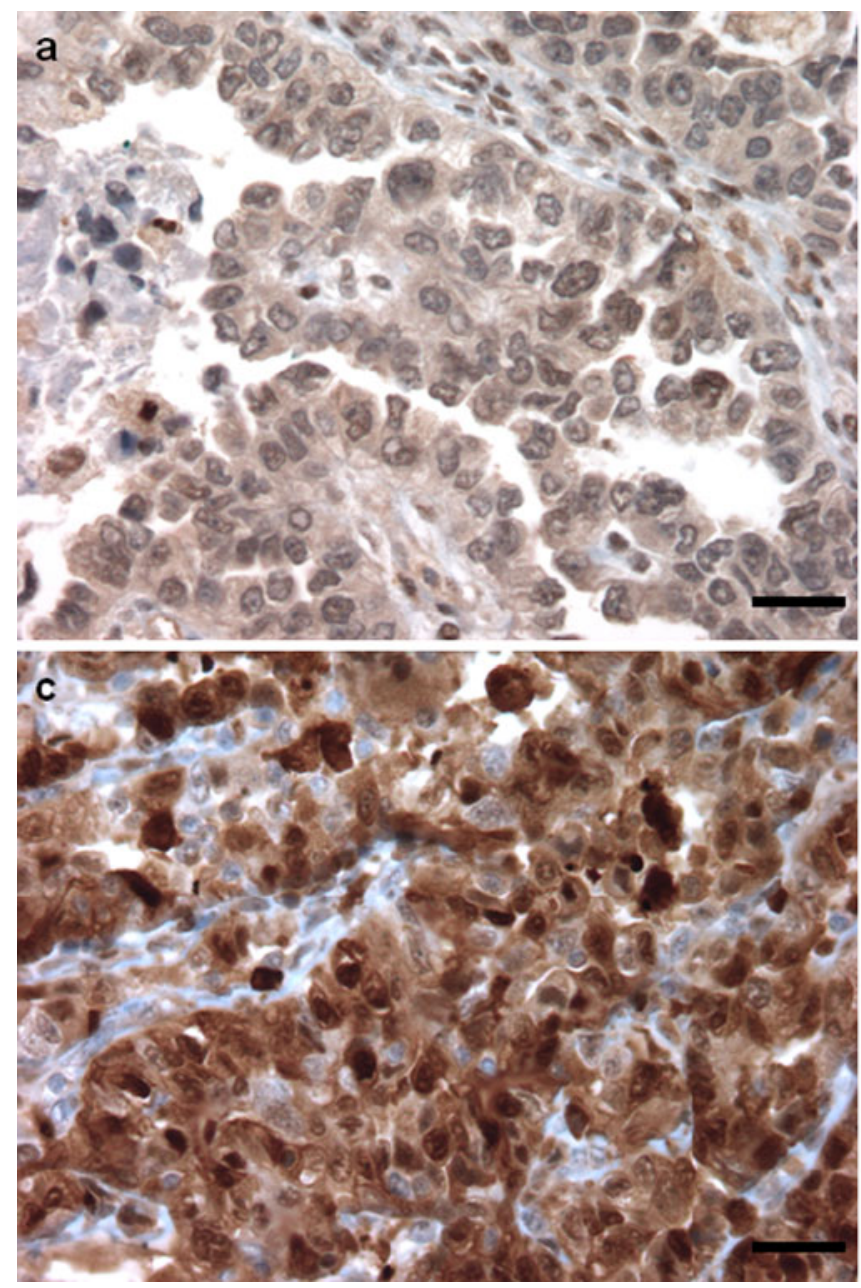

Fig. 3 Immunohistochemical studies using a polyclonal antibody directed against the C-terminal portion of the Reg-alpha fragment. This study was performed on 12 different samples (see Table 2). This set of pictures represents carcinoma tissues. a Papillary clear-cell

The difference in cellular localization based on the benign or malignant character of the epithelial samples is illustrated in Figs. 3 and 4. Moreover, in these surface epithelial-stromal tumors types, both epithelial and stroma cells are labeled in IHC with the anti-C-terminal Reg-alpha antibody. It is now possible to discriminate through the localization of the labeling (nuclear vs. cytoplasmic), these tumors which are a class of ovarian neoplasms that may be benign or malignant. It has to be noted that in this group of tumors serum CA-125 is often elevated but is only $50 \%$ accurate, so it is not a useful tumor marker to assess the progress of treatment. We have now a novel marker, Reg alpha, which completes the diagnosis. Statistical analyses performed for this marker at different OVC stages reflect a prevalence of $77.66 \pm 8.77$ (with a correlation coefficient value of $p<0.001$ of 0.601 between OVC and benign tissue) (Table 3 ).

Considering this strict difference, we then investigated the presence of C-terminal Reg-alpha fragment in the
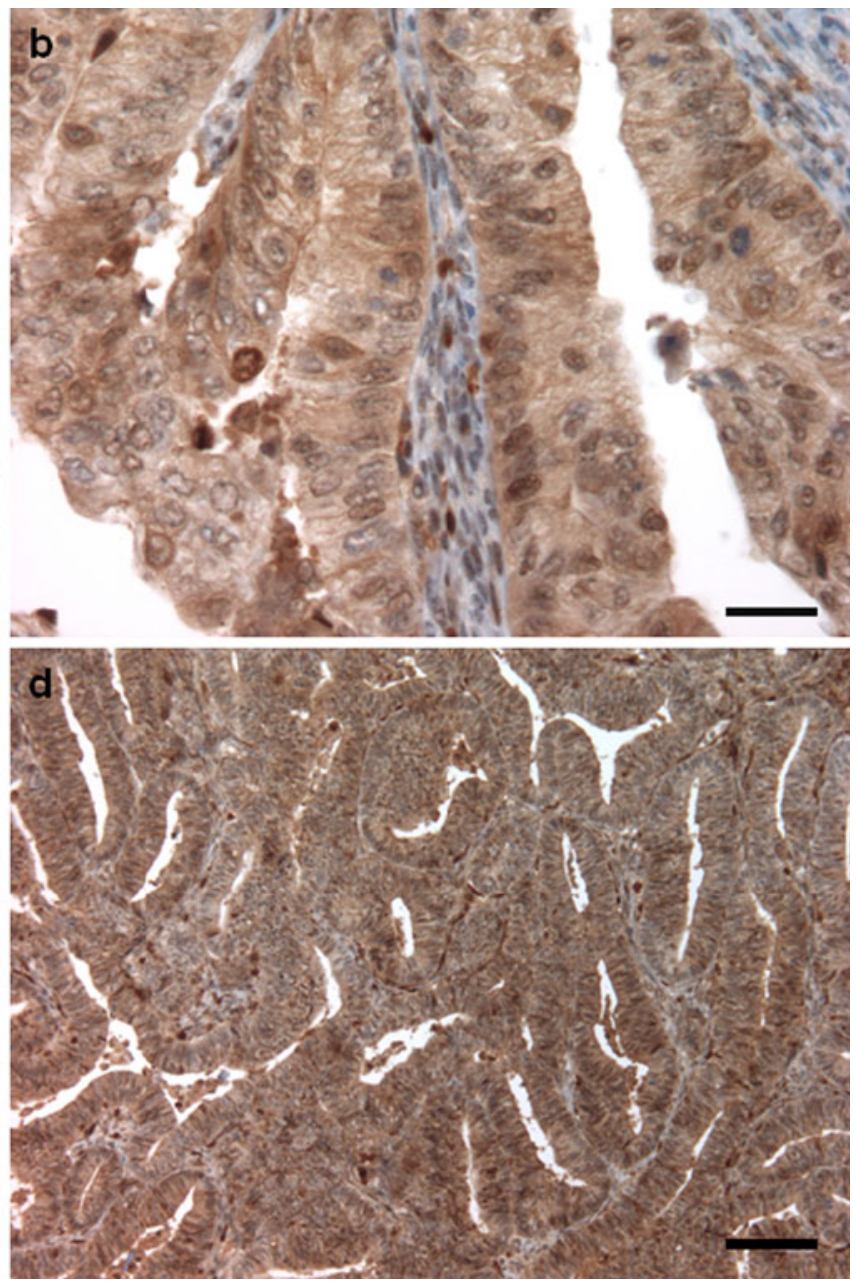

carcinoma (scale bar $50 \mu \mathrm{m})$. b Epithelial cells of immunolabeled serous carcinoma (scale bar $50 \mu \mathrm{m}$ ). c Epithelial cells of immunolabeled serous poorly differentiated carcinoma (scale bar $50 \mu \mathrm{m}$ ). d Endometrioid carcinoma (scale bar $50 \mu \mathrm{m}$ )

borderline tissues (Fig. 5). Ten tissues were investigated in IHC. The borderline cysts (Fig. 5) revealed strong labeling in the cytoplasm and nucleus, which indicated a malignant diagnosis for these samples. The HFIP-based MALDI profiling analyses for the 12 samples (Fig. 6) confirm the presence of the marker in the malignant portion, and its absence in the healthy portion of the ovary (Fig. 6) confirmed the specificity and usefulness of Reg alpha for diagnosing borderline tumors. Thus, the presence of the Reg-alpha C-terminal fragment with an $\mathrm{m} / \mathrm{z}$ ratio of 9,744 confirms the malignant character of the tissue.

\section{The C-terminal Reg-alpha fragment is a specific OVC-relapse diagnosis marker}

Treatment for advanced OVC involves an explorative celioscopic surgery followed by a neoadjuvant treatment 

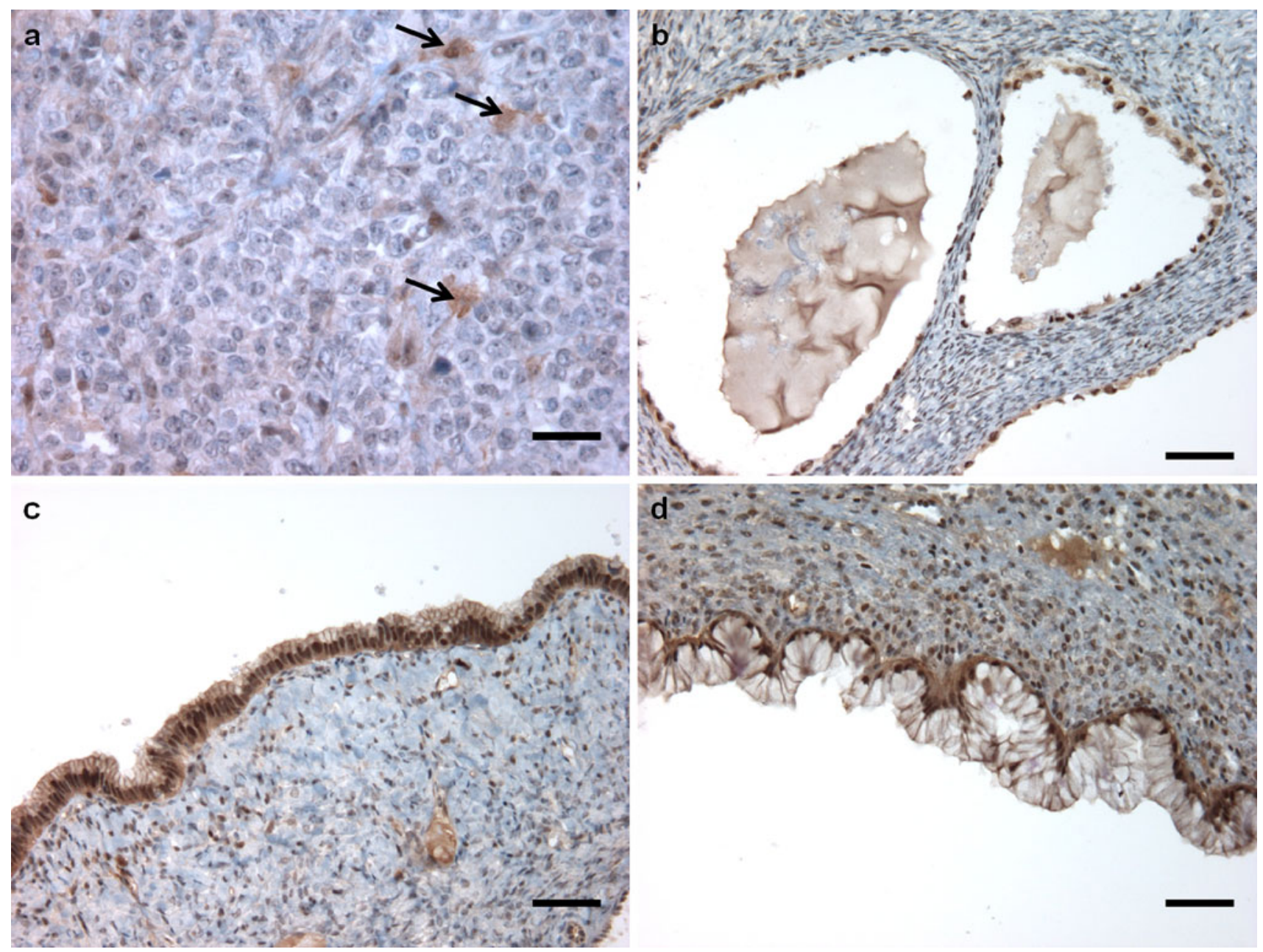

Fig. 4 Immunohistochemical studies using a polyclonal antibody directed against the C-terminal portion of Reg alpha. This study was performed on 12 different samples (see Table 2). This set of pictures represents carcinoma and benign tissues. a Epithelial cytoplasmic labeling of the undifferentiated contingent on the endometrioid

carcinoma (scale bar $50 \mu \mathrm{m}$ ). b Mucinous invasive carcinoma (scale bar $200 \mu \mathrm{m}$ ). c Serous cystadenomas (benign ovary tissue; scale bar $50 \mu \mathrm{m}$ ). d Mucinous cystadenocarcinoma (benign ovary tissue; scale bar $50 \mu \mathrm{m})$

with paclitaxel and platinum, or carboplatin with taxol (Lhomme et al. 2009) if carcinosis is visible during the explorative celioscopic surgery. The patients for whom this chemotherapy was effective had their reproductive organs (i.e., ovaries, fallopian tubes, and uterus; Table 4) completely removed at least 10 months after the initial diagnosis. The 5-year survival remains poor at about $40 \%$ (Kehoe 2008; Tanner et al. 2012). The responders will relapse within approximately 18 months after completing first-line therapy and require further systemic therapy. The median survival of patients with recurrent ovarian cancer ranges from 12 to 24 months. Traditional clinical measures of relapse include disease progression, usually defined as a $25 \%$ or greater increase in tumor size, appearance of new lesions, or death.

In this context, ten patients were surgically explored by celioscopy. The carcinosis samples from the first surgery or

the ovarian samples from the second surgery were analyzed for tumor recurrence by tracking the C-terminal Reg-alpha fragment using MALDI-MS profiling (Fig. 7). The C-terminal Reg-alpha fragment was present in the mass spectra of these patients. In patient 97, for example, the chemotherapeutic treatment was completely ineffective. In this patient, all of the samples taken during the exploratory celioscopy (the second surgery) were malignant, and the C-terminal Reg-alpha fragment was found in all of the biopsies. For patients 66 (Fig. 7 see inset 66) and 81, the relative efficacy of the chemotherapy allowed the surgeon to perform the radical surgery; however, the patients are still under surveillance. A biopsy from patient 75 that was collected 7 months after the treatment also presented a small peak with an $\mathrm{m} / \mathrm{z}$ ratio of 9,744 , confirming that the tumor was still present and that relapse might be beginning (Fig. 7; see inset 75). Consequently, this patient received 
Table 2 The immunohistochemistry results from 12 patients

\begin{tabular}{|c|c|c|c|c|c|}
\hline & Patients & Pathologist diagnosis & $\begin{array}{l}\text { Epithelial labeling } \\
\text { intensity }\end{array}$ & $\begin{array}{l}\text { Cellular localization } \\
\text { of the labeling }\end{array}$ & Stroma reaction \\
\hline \multirow[t]{8}{*}{ Ovarian cancer } & 1 & $\mathrm{ADK}$ & Strong & Cytoplasmic and nuclear & Low and nuclear \\
\hline & 2 & Papillary carcinoma & Strong & Cytoplasmic and nuclear & Low and nuclear \\
\hline & 3 & Mucinous ADK & Strong & Cytoplasmic and nuclear & Low and nuclear \\
\hline & 4 & Serous ADK less differentiated & Strong & Cytoplasmic and nuclear & Low and nuclear \\
\hline & 5 & ADK less differentiated invasive & Strong & Cytoplasmic and nuclear & Low and nuclear \\
\hline & 6 & Borderline cyst & Strong & Cytoplasmic and nuclear & Low and nuclear \\
\hline & 7 & Endometrioid ADK & Strong & Cytoplasmic and nuclear & Low and nuclear \\
\hline & 8 & Endometrioid ADK & Strong & Cytoplasmic and nuclear & Low and nuclear \\
\hline \multirow[t]{7}{*}{ Benign ovarian tumors } & 1 & Serous cystadenocarcinoma & Strong & Nuclear & Low and nuclear \\
\hline & 2 & Adenocarcinoma borderline & Strong & Nuclear & Low and nuclear \\
\hline & 3 & Benign part of serous ADK & Low & Nuclear & Low and nuclear \\
\hline & 4 & Serous cystadenocarcinoma & Low & Nuclear & Low and nuclear \\
\hline & 5 & Leiomyoma & Low & Nuclear & Low and nuclear \\
\hline & 6 & Mucinous cystadenocarcinoma & Strong & Nuclear & Low and nuclear \\
\hline & 7 & Serous cyst & Strong & Nuclear & Low and nuclear \\
\hline
\end{tabular}

The immunohistochemistry used an antibody directed against the C-terminal fragment of the 11s proteasome activator complex (PA28, Reg alpha)

Table 3 Statistical analyses of detection of Reg-alpha marker in the different cases

\begin{tabular}{ll}
\hline Pathology type & $\begin{array}{l}\text { Statistical prevalence } \\
\text { of the C-terminal fragment }(\%) ; \\
\text { (time detection/number of samples) }\end{array}$
\end{tabular}

$\begin{array}{lc}\text { Serous cancer } & \\ \text { Stage I } & 66 \% ;(14 / 21) \\ \text { Stage III-IV } & 80.5 \% ;(95 / 118) \\ \text { Relapse } & 88 \% ;(22 / 25) \\ \text { Mucinous cancer } & \\ \text { Stage III-IV } & 82 \% ;(41 / 50) \\ \text { Borderline } & 71.8 \% ;(23 / 32) \\ \text { Benign } & 20 \% ;(26 / 130)\end{array}$

The method used for statistics takes into account all techniques used for the detection of this maker. This includes MALDI profiling, IHC, Western blot, nano-LC-IT-MS, and MALDI-MSI. Considering the technique used, this marker is detected at $73 \%$ in IHC, $89 \%$ in MALDI profiling, and $77 \%$ in MALDI-MSI combined with Western. MALDI profiling seems to be the best technology to detect this marker. The variation intra-essay of the detection of this marker is $12 \%$ between OVC and benign tissues

radical surgery and is now under surveillance. The positive control for the experiment was the detection of the C-terminal Reg-alpha fragment in the mass spectra of patients 67 and 79, who had BRCA1 genetic mutation and breast cancer. Pathology-based recidivism was observed in patient 66 (Fig. 7 see inset 66), confirming that the presence of the C-terminal Reg-alpha fragment could be used to evaluate pathological resurgence or persistence. This demonstrates that this marker (C-terminal fragment of Reg alpha) can detect tumor recurrence and can be used to monitor relapse and treatment efficacy. This marker presents a prevalence of $88 \%$ in the case of tumor relapse (Table 4).

\section{The C-terminal Reg-alpha fragment is a specific early-stage OVC-diagnosis marker}

A good marker for disease screening must be found in the early stages of disease development. We obtained stage I surgical tissues from different types of OVCs. We then investigated the C-terminal Reg-alpha fragment in the cancerous regions of interest by comparing the molecular profiles of small areas of cancerous tissue with normal areas from the same tissue section. Due to the difficulty of diagnosis at the early stage of pathology, this study was performed on eight collected tissues. Figures 8 and 9 show the restricted size of the diseased areas from stage 1a and stage 1c serous OVC biopsies, respectively. The relative spectra acquired in each cancerous and benign tissue zone focus on the mass range of Reg alpha and confirm that it is present only in the OVC cells. The spectra clearly show that this marker is specifically localized in the cancerous regions of the OVC tissue and is absent in the benign tissue areas. The immunofluorescence data confirmed the localization of the C-terminal Reg-alpha fragment in the three cells of the acini (Fig. 8; see inset picture). Moreover, we confirmed the presence of Reg alpha in stage I tissues from the most frequent OVC-epithelial cancer types: 


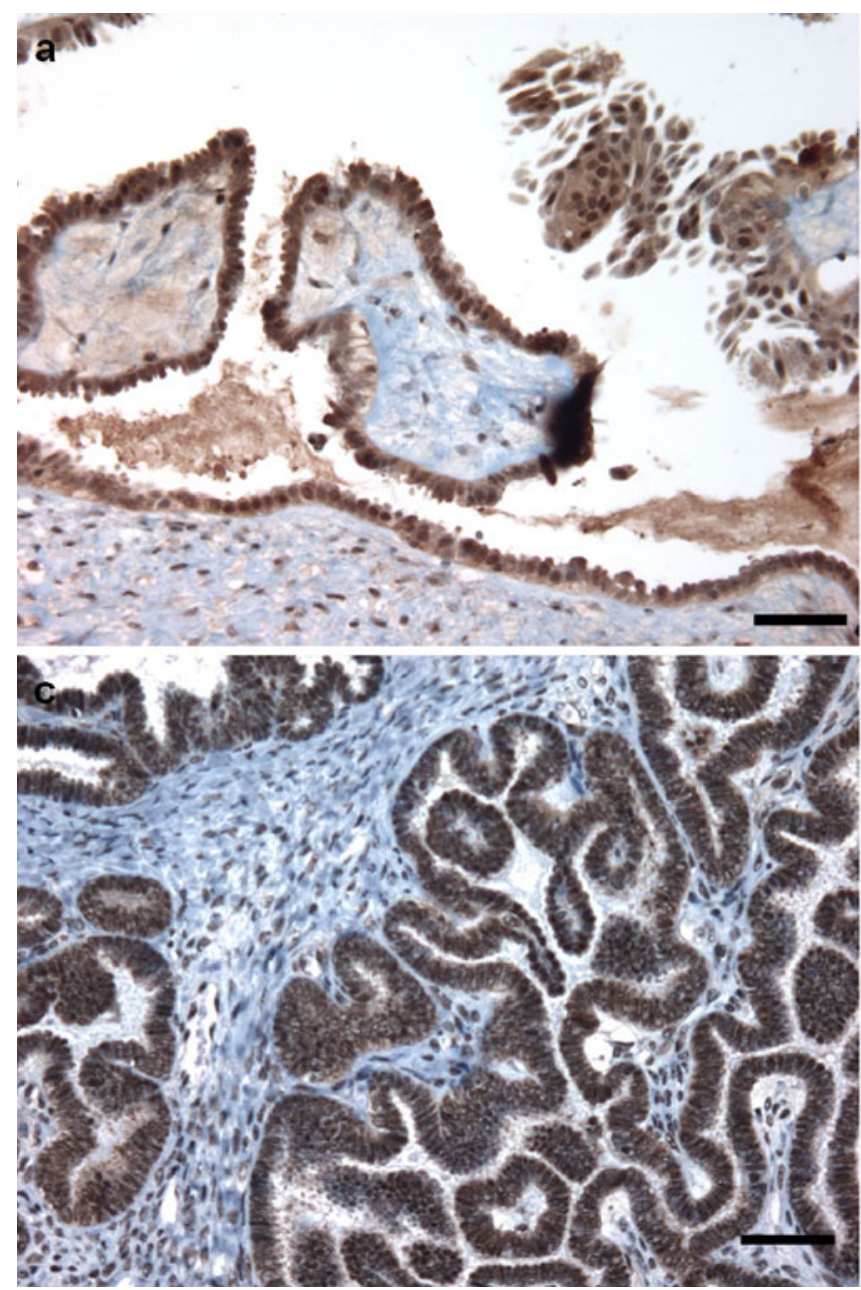

Fig. 5 Immunohistochemical studies using a polyclonal antibody directed against the C-terminal portion of Reg alpha. This study was performed on samples from 12 different patients (see Table 2). This set of pictures represents borderline tissues. a A borderline malignant

endometrioid (Fig. 9), which represents $15 \%$ of epithelial OVC cases; mucinous OVC (Fig. 10), which represents $5 \%$ of OVC cases; and serous OVC (Fig. 2), which represents $80 \%$ of OVC cases. We also found this marker in borderline mucinous tissue. Statistically, Reg alpha is detected at $81.25 \% \pm 1.06$ in stage III-IV and $80.5 \%$ in stage I of OVC (Table 3). The correlation coefficient for all OVC stages is $p<0.001$ of 0.998 .

\section{Discussion}

These data confirmed that our novel method was useful for rapid diagnosis using small pieces of tissue taken from extemporaneous biopsies. This procedure can be used for extemporaneous biopsies and will help pathologists provide a diagnosis. Indeed, the extemporaneous analysis of
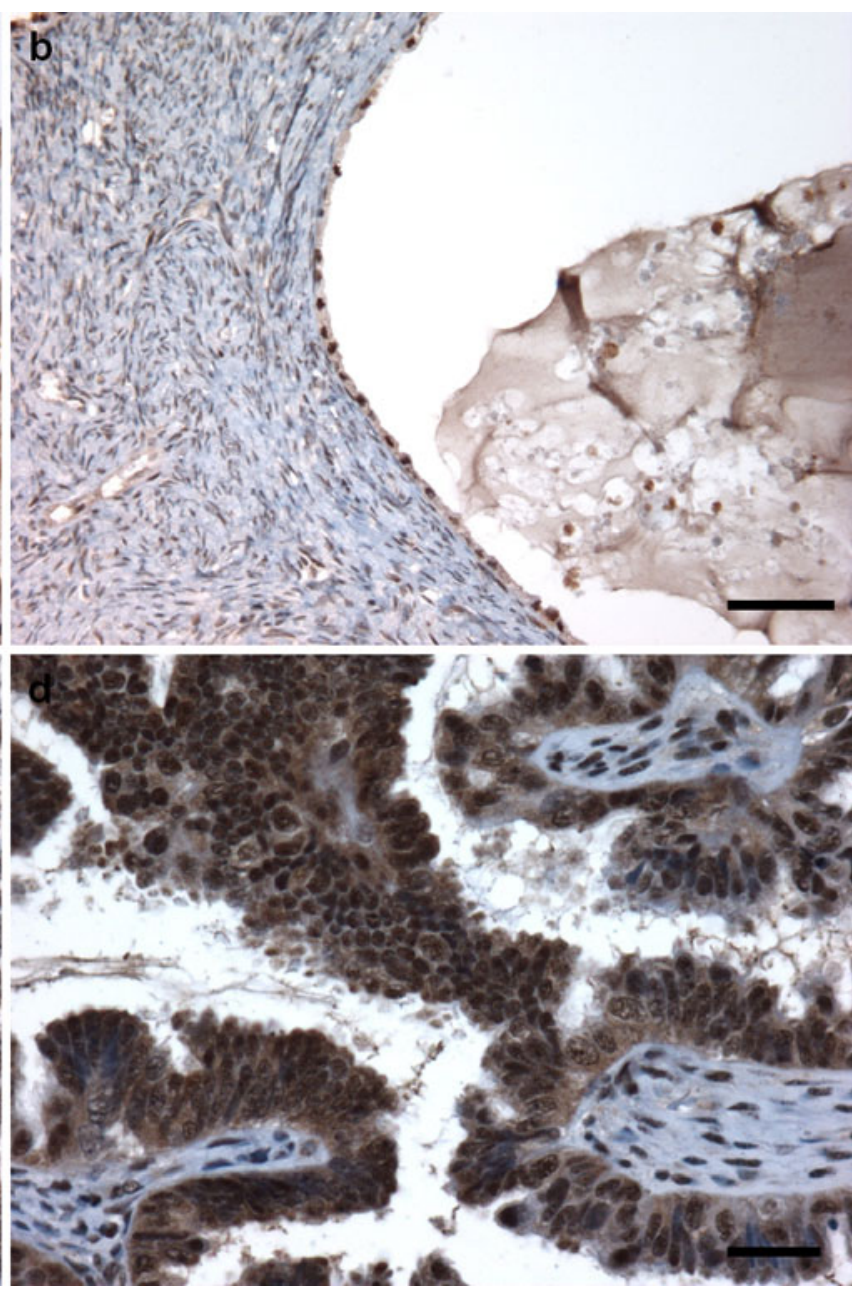

cyst (scale bar $50 \mu \mathrm{m}$ ). b Borderline adenocarcinoma tissue (benign tissue; scale bar $200 \mu \mathrm{m}$ ). c Borderline malignant mucinous tissue (scale bar $200 \mu \mathrm{m}$ ). d Borderline malignant mucinous tissue (scale bar $50 \mu \mathrm{m})$

tissue sections usually relies on a simple visual evaluation of the HES section of the biopsy. The final pathological reports confirm the initial diagnosis using IHC for known pathological biomarkers, such as P53 and HER2/neu, and are only available 1 week later. This rapid and simple method can be used for fast tissue marker analysis that provides additional disease information to the pathologist and the surgeon for use in the extemporaneous analysis that will be followed by the IHC-based final report.

Therefore, the C-terminal Reg-alpha fragment biomarker has been detected in early- and late-stage OVC using MALDI mass spectrometry profiling with a specific HFIP extraction procedure. The presence of Reg alpha in certain borderline tissues illustrates its usefulness in cases that are difficult to diagnose. This marker can also be used to evaluate cancer treatment, and its presence in patients after chemotherapy and tumor relapse confirms that this 
Fig. 6 MALDI-MS spectra of the HFIP extracts from a mucinous borderline region. The ion with an $\mathrm{m} / \mathrm{z}$ of 9,774 ratio corresponds to the C-terminal Reg-alpha fragment and is indicated by an arrow. The HFIP extraction from the healthy region confirmed the absence of the ion at an $\mathrm{m} / \mathrm{z}$ of 9,774 , validating the specificity of the C-terminal fragment detection. These data demonstrate that this borderline tissue is malignant. The inset illustrates hematoxylin and eosin (H\&E) staining of the tissue subjected to MALDI-MS profiling analyses (scale bar $5 \mathrm{~mm}$ )

Table 4 The characteristics of the patients from whom tissue was collected after neoadjuvant chemotherapy

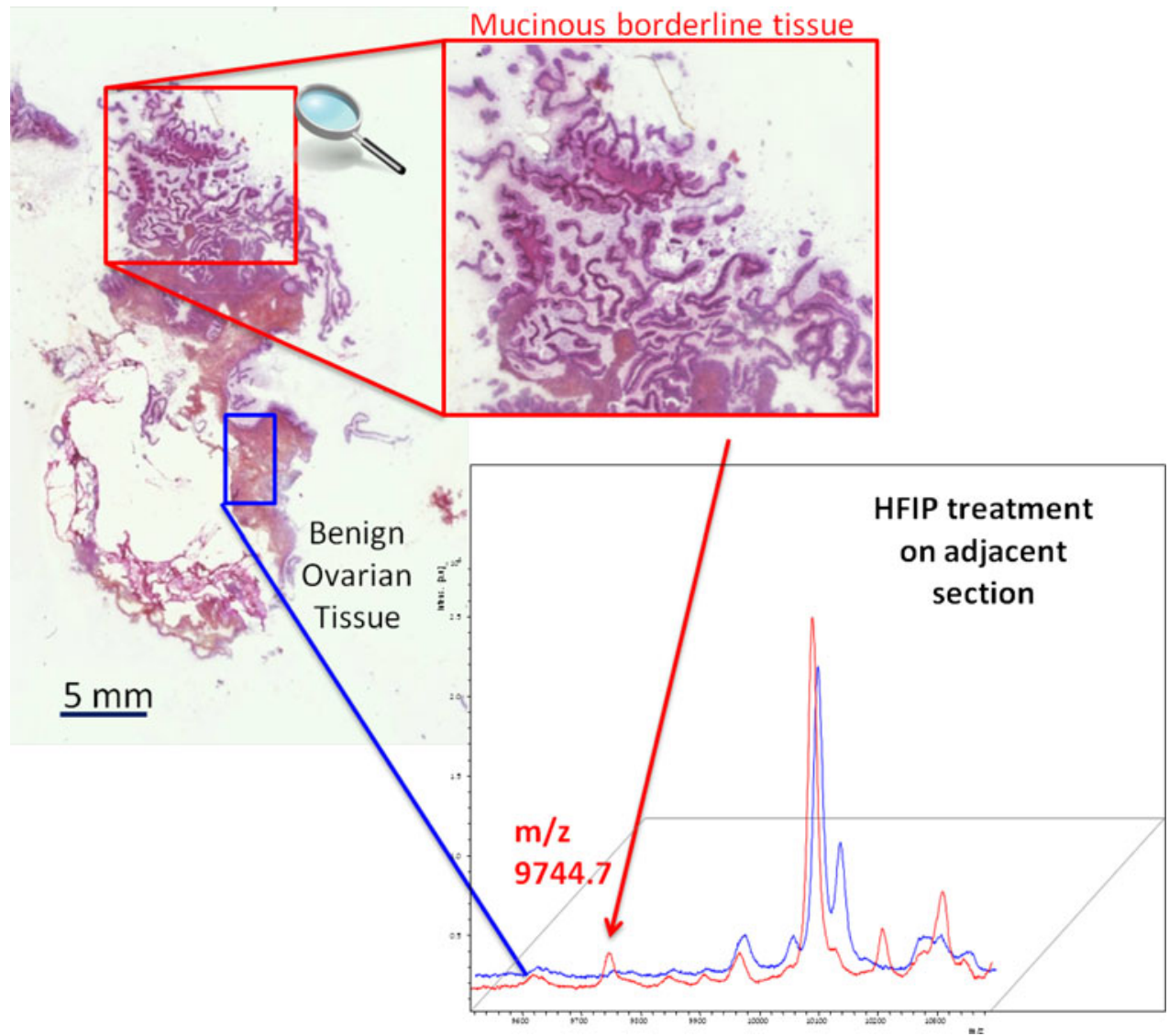

\begin{tabular}{|c|c|c|c|c|}
\hline $\begin{array}{l}\text { Patient } \\
\text { number }\end{array}$ & $\begin{array}{l}\text { Patient } \\
\text { age }\end{array}$ & Observations & Type of treatment & $\begin{array}{l}\text { Time between the } \\
\text { diagnosis and second } \\
\text { surgery (months) }\end{array}$ \\
\hline 58 & 58 & & $\begin{array}{l}6 \text { Cycles of carboplatin/taxol } \\
\text { Complete surgery }\end{array}$ & 4 \\
\hline 65 & 61 & & $\begin{array}{l}6 \text { Cycles of carboplatin/taxol } \\
\text { Complete surgery }\end{array}$ & 10 \\
\hline 66 & 69 & & $\begin{array}{l}6 \text { Cycles of carboplatin/taxol } \\
\text { Complete surgery carboplatin/Caelyx }\end{array}$ & 15 \\
\hline 67 & 55 & Mutation BRCA1 & $\begin{array}{l}4 \text { Cycles of carboplatin/taxol } \\
\text { Complete surgery } \\
2 \text { Cycles of carboplatin/taxol }\end{array}$ & 8 \\
\hline 69 & 63 & & $\begin{array}{l}4 \text { Cycles of carboplatin/taxol } \\
\text { Complete surgery } \\
2 \text { Cycles of carboplatin/taxol }\end{array}$ & 8 \\
\hline 75 & 60 & & $\begin{array}{l}6 \text { Cycles of carboplatin/taxol } \\
\text { Complete surgery }\end{array}$ & 7 \\
\hline 79 & 59 & $\begin{array}{l}\text { Mutation BRCA1 } \\
\text { and breast } \\
\text { cancer associated }\end{array}$ & $\begin{array}{l}6 \text { Cycles of carboplatin/taxol } \\
\text { Radiotherapy and herceptin }\end{array}$ & 1 \\
\hline 81 & 48 & & $\begin{array}{l}6 \text { Cycles of carboplatin/taxol } \\
\text { Complete surgery }\end{array}$ & 11 \\
\hline 95 & 65 & & $\begin{array}{l}6 \text { Cycles of carboplatin/taxol } \\
\text { Taxol }\end{array}$ & 12 \\
\hline 97 & 59 & & $\begin{array}{l}6 \text { Cycles of carboplatin/taxol } \\
\text { Taxol }\end{array}$ & 18 \\
\hline
\end{tabular}




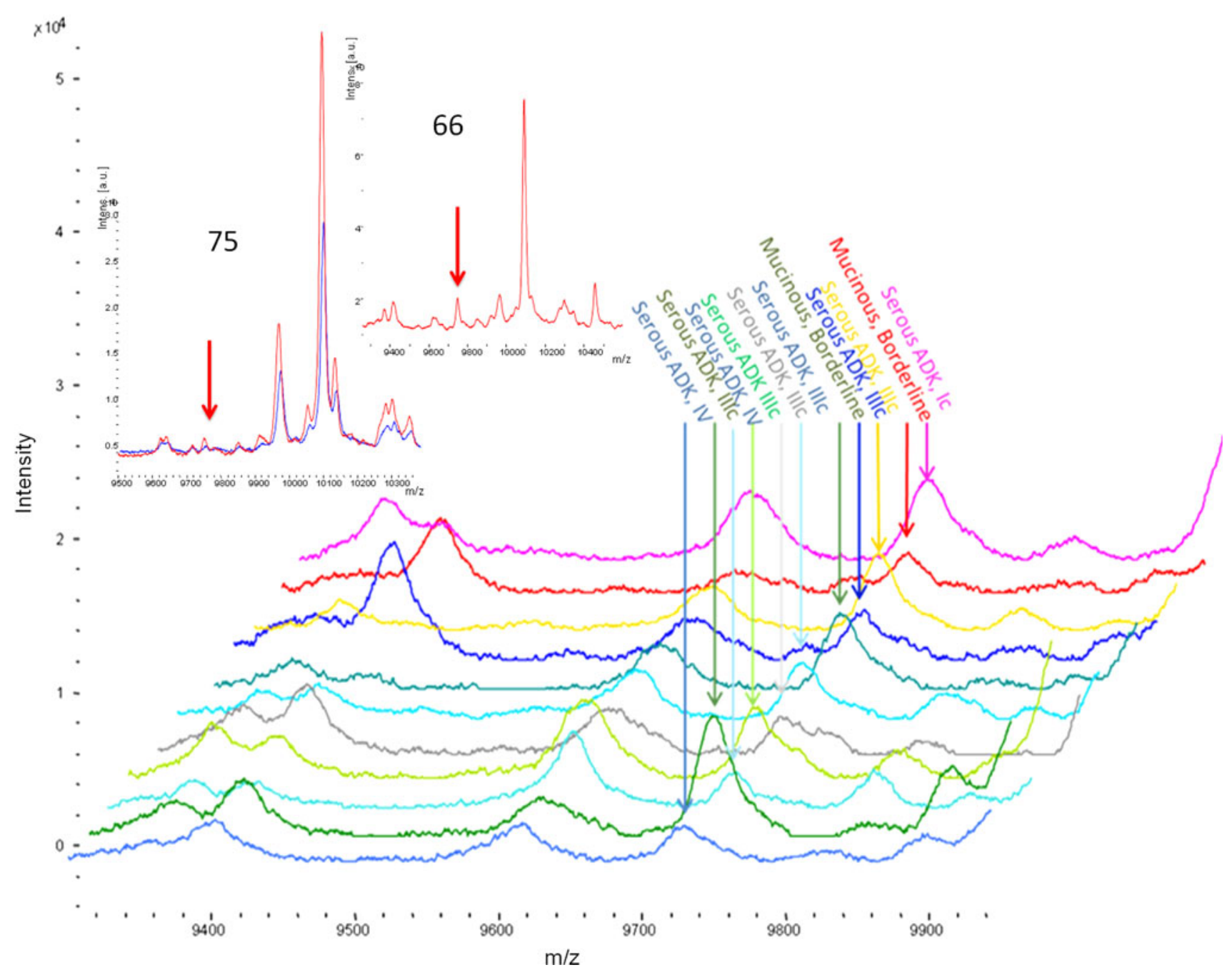

Fig. 7 MALDI-MS spectra of the HFIP extracts from the carcinoma regions of ten patients at different pathologic stages after neoadjuvant chemotherapy. Mass spectra analyses of HFIP extracts from stages I, IIIc, and IV serous tumors after neoadjuvant chemotherapy. The ion with an $\mathrm{m} / \mathrm{z}$ ratio of 9,774 corresponds to the C-terminal Reg-alpha fragment, is found in each patient, and is indicated by an arrow. These data confirm that the C-terminal fragment of Reg alpha can be a good marker for the early diagnosis of tumor relapse. (inset 75 a

protein fragment is a promising candidate for monitoring patient response during therapy. The data obtained by MALDI mass spectrometry profiling are consistent with the IHC data.

A specific antibody allows for discriminating malignant from benign cells and can be useful for diagnosing borderline tissues. In this context, we performed IHC on borderline tissues and confirmed the specificity of Reg alpha in tissue for which a specific diagnosis was difficult. The borderline OVC stage constitutes a precancerous lesion, confirming that the Reg-alpha C-terminal fragment is an early marker of ovarian tumors and can be used as a screening marker for this pathology. Our specific mass tissue analysis example from a patient subjected to 15 months of prior neoadjuvant chemotherapy with 6 cycles of carboplatin/taxol followed by carboplatin with Caelyx before complete surgery. The ion corresponding to the C-terminal Reg-alpha fragment $(\mathrm{m} / \mathrm{z} 9,744)$ is detected. Inset 66 a tissue analysis example from a patient subjected to 7 months of prior neoadjuvant chemotherapy with six cycles of carboplatin/taxol. The ion corresponding to the C-terminal Reg-alpha fragment $(\mathrm{m} / \mathrm{z} 9,744)$ is detected)

spectrometry protocol obtains molecular information in under $10 \mathrm{~min}$, as compared to $2 \mathrm{~h}$ for IHC. This technology will give the pathologist a new diagnostic tool that may be particularly useful for extemporaneous biopsy diagnosis.

In ovarian cancer, the median interval to the first recurrence is $18-24$ months. After recurrence, approximately $70 \%$ of advanced-stage ovarian cancer cases relapse, and even in stage I or II patients, the relapse rate is $20-25 \%$. Half of the recurrences occur more than 12 months after the end of first-line therapy, and onequarter of all recurrences occur within less than 6 months. A single carboplatin cycle has been a standard regimen for patients with platinum-sensitive disease. A phase II trial of 
Fig. 8 MALDI-MS spectra of HFIP extracts from stage 1a serous OVC biopsies. The C-terminal Reg-alpha fragment $(\mathrm{m} / \mathrm{z} 9,744)$ is detected in the acini cells. The inset shows fluorescent immunocytochemistry data using the anti-C-terminal Regalpha fragment and hematoxylin and eosin (H\&E) staining of the tissue subjected to MALDI-MS profiling analyses (scale bar $5 \mathrm{~mm}$ )

Fig. 9 MALDI-MS spectra of HFIP extracts from stage 1c serous OVC biopsies. The C-terminal Reg-alpha fragment $(\mathrm{m} / \mathrm{z} 9,744)$ is detected in the OVC cells. The inset shows the hematoxylin and eosin (H\&E) staining of the tissue subjected to MALDI-MS profiling analyses (scale bar $5 \mathrm{~mm}$ )
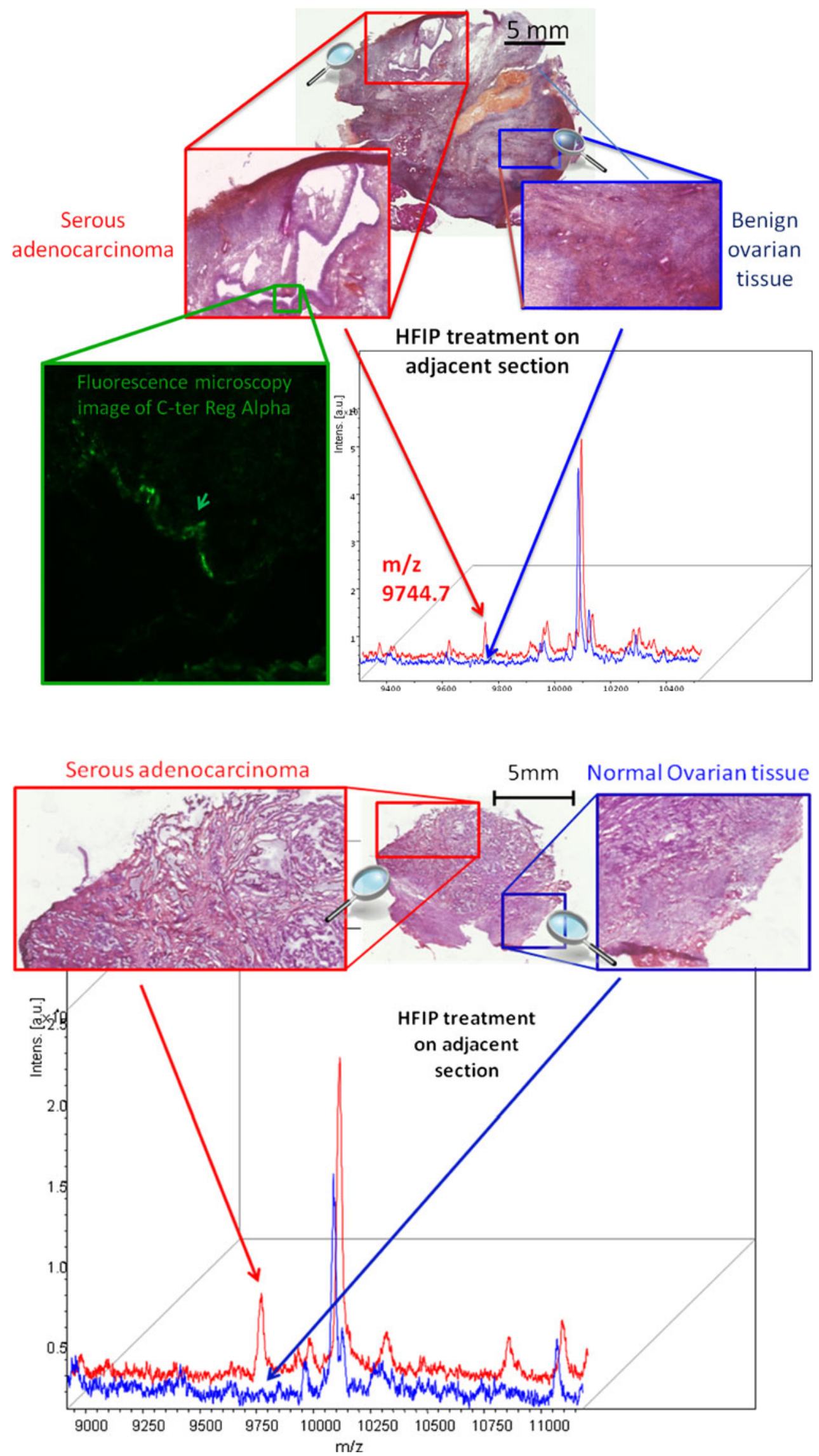
Fig. 10 MALDI-MS spectra of HFIP extracts from stage 1c endometrioid OVC biopsies or from healthy adjacent tissue. The C-terminal fragment of Reg-alpha (m/z 9,744) is detected in the tumor sample. The inset shows the hematoxylin and eosin (H\&E) staining of the tissue subjected to MALDI-MS profiling analyses (scale bar $5 \mathrm{~mm}$ )

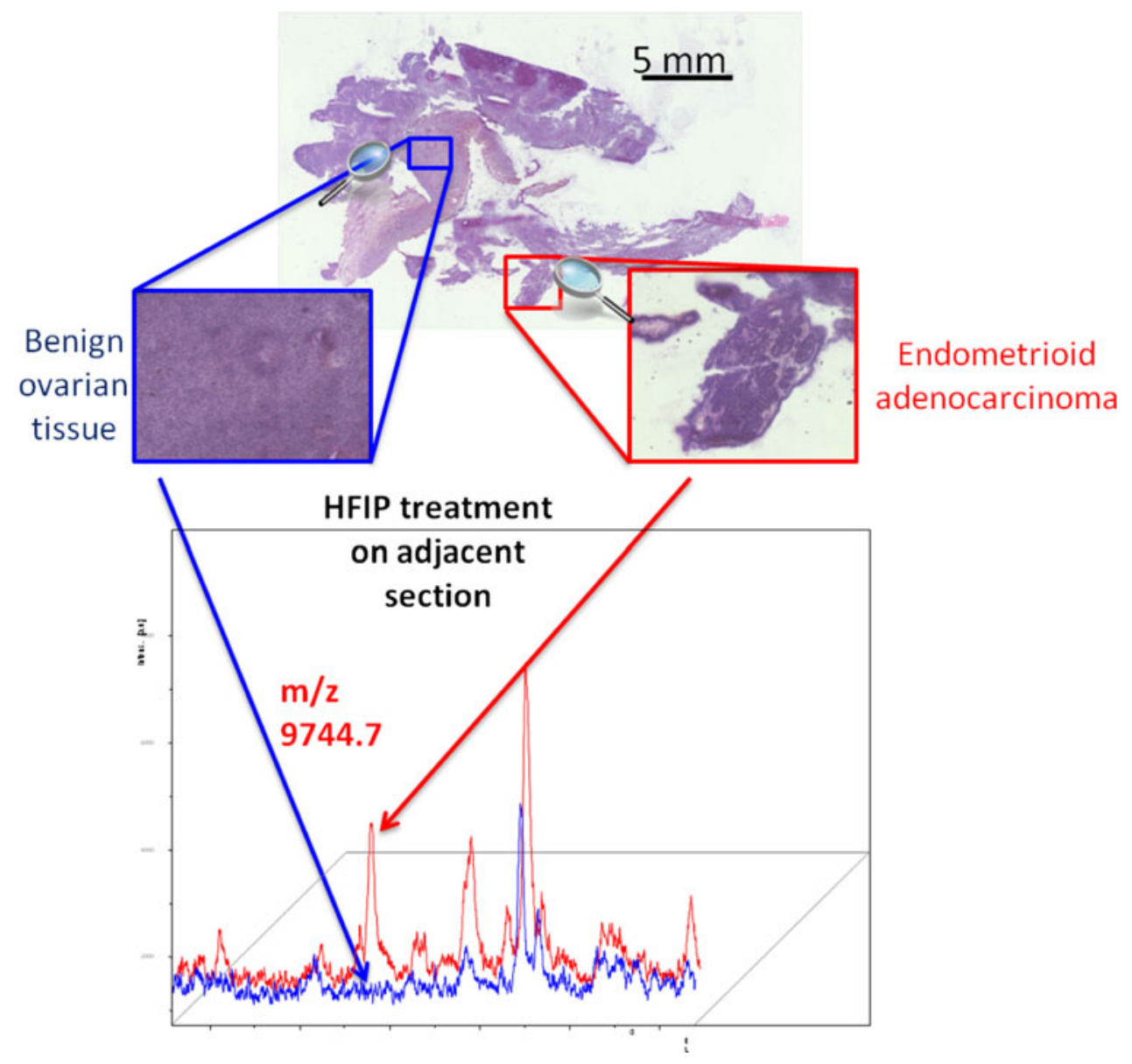

a paclitaxel and carboplatin combination for sensitive (6 months) patients is currently used after phase I (Ushijima 2010). Patients with persistent ovarian cancer have cancer cells that are detected after initial surgery and first-line chemotherapy. Persistent ovarian cancer is detected by elevated serum CA-125, abnormal X-rays and CT scans, or a biopsy performed during a second-look laparotomy. The standard course of the initial chemotherapy is approximately six cycles (or 4 months of treatment). It is thus important to have good tumor-relapse markers to evaluate whether the first-line treatment is sufficient or whether a second cycle of chemotherapy is necessary. In this context, the C-terminal Reg-alpha fragment is a good candidate for evaluating tumor treatment resistance. In fact, the marker is useful soon after treatment, because it can be detected 1 month after 6 cycles of carboplatin/Taxol followed by pharmacologic treatments (Table 3). This marker can also be used in conjunction with mucin-9, which we have previously identified in tumors (El Ayed et al. 2010; Franck et al. 2009a) and in patients' serum (Maines-Bandiera et al. 2010). Notably, the C-terminal Regalpha fragment has also been detected in ascites fluid (El Ayed, unpublished data). Therefore, these two markers can be used to track the therapeutic efficacy.
Acknowledgments This study was supported by grants from the Agence Nationale de la Recherche (ANR PCV to IF), Institut du Cancer (INCA to IF), Institut de Recherche en Santé du Canada (ISRC to MS \& RD), Ministère du Développement Économique de l'Innovation et de l'Exportation (MDEIE to R.D), Fonds de recherche du Québec-Santé (FRQS to R.D), C.H.R. U. Lille (to CB) and Région Nord-Pas de Calais (to RL). R.D. is a member of the Centre de Recherche Clinique Etienne-Le Bel (Sherbrooke, QC, Canada).

\section{References}

Bonnel D, Longuespee R, Franck J, Roudbaraki M, Gosset P, Day R, Salzet M, Fournier I (2011) Multivariate analyses for biomarkers hunting and validation through on-tissue bottom-up or in-source decay in MALDI-MSI: application to prostate cancer. Anal Bioanal Chem 401:149-165

Caprioli RM, Farmer TB, Gile J (1997) Molecular imaging of biological samples: localization of peptides and proteins using MALDI-TOF MS. Anal Chem 69:4751-4760

Cornett DS, Mobley JA, Dias EC, Andersson M, Arteaga CL, Sanders ME, Caprioli RM (2006) A novel histology-directed strategy for MALDI-MS tissue profiling that improves throughput and cellular specificity in human breast cancer. Mol Cell Proteomics 5:1975-1983

Djidja MC, Claude E, Snel MF, Francese S, Scriven P, Carolan V, Clench MR (2010) Novel molecular tumour classification using 
MALDI-mass spectrometry imaging of tissue micro-array. Anal Bioanal Chem 397:587-601

El Ayed M, Bonnel D, Longuespee R, Castelier C, Franck J, Vergara D, Desmons A, Tasiemski A, Kenani A, Vinatier D, Day R, Fournier I, Salzet M (2010) MALDI imaging mass spectrometry in ovarian cancer for tracking, identifying, and validating biomarkers. Med Sci Monit 16:BR233-245

Franck J, Arafah K, Elayed M, Bonnel D, Vergara D, Jacquet A, Vinatier D, Wisztorski M, Day R, Fournier I, Salzet M (2009a) MALDI imaging mass spectrometry: state of the art technology in clinical proteomics. Mol Cell Proteomics 8:2023-2033

Franck J, El Ayed M, Wisztorski M, Salzet M, Fournier I (2009b) On-tissue $\mathrm{N}$-terminal peptide derivatizations for enhancing protein identification in MALDI mass spectrometric imaging strategies. Anal Chem 81:8305-8317

Franck J, Longuespee R, Wisztorski M, Van Remoortere A, Van Zeijl R, Deelder A, Salzet M, McDonnell L, Fournier I (2010) MALDI mass spectrometry imaging of proteins exceeding 30,000 daltons. Med Sci Monit 16:BR293-299

Kehoe S (2008) The management of ovarian carcinoma. Minerva Ginecol 60:155-164

Longuespée R, Charlotte B, Kerdraon, O, Vinatier D, Fournier I, Day R, Salzet M (2012) MALDI MSI and ovarian cancer biomarkers. Adv Cancer Manag Ed Mohan R:211-236

Khalil I, Brewer MA, Neyarapally T, Runowicz CD (2010) The potential of biologic network models in understanding the etiopathogenesis of ovarian cancer. Gynecol Oncol 116:282-285

Lambaudie E, Collinet P, Vinatier D (2006) Ovarian cancers and CA 125 in 2006. Gynecol Obstet Fertil 34:254-257

Lemaire R, Lucot JP, Collinet P, Vinatier D, Tabet JC, Salzet M, Fournier I (2005) New developments in direct analyses by MALDI mass spectrometry for study ovarian cancer. Mol Cell Proteomics 4:S305-S308

Lemaire R, Tabet JC, Ducoroy P, Hendra JB, Salzet M, Fournier I (2006a) Solid ionic matrixes for direct tissue analysis and MALDI imaging. Anal Chem 78:809-819

Lemaire R, Wisztorski M, Desmons A, Tabet JC, Day R, Salzet M, Fournier I (2006b) MALDI-MS direct tissue analysis of proteins: improving signal sensitivity using organic treatments. Anal Chem 78:7145-7153

Lemaire R, Desmons A, Tabet JC, Day R, Salzet M, Fournier I (2007a) Direct analysis and MALDI imaging of formalin-fixed, paraffin-embedded tissue sections. J Proteome Res 6:1295-1305

Lemaire R, Menguellet SA, Stauber J, Marchaudon V, Lucot JP, Collinet P, Farine MO, Vinatier D, Day R, Ducoroy P, Salzet M, Fournier I (2007b) Specific MALDI imaging and profiling for biomarker hunting and validation: fragment of the $11 \mathrm{~S}$ proteasome activator complex, Reg alpha fragment, is a new potential ovary cancer biomarker. J Proteome Res 6:4127-4134

Lhomme C, Even C, Morice P, Balleyguier C, Petrella M, Gouy S, Uzan C, Duvillard P, Pautier P (2009) First line chemotherapy of advanced epithelial ovarian cancer. Bull Cancer 96:1207-1213
Maines-Bandiera S, Woo MM, Borugian M, Molday LL, Hii T, Gilks B, Leung PC, Molday RS, Auersperg N (2010) Oviductal glycoprotein (OVGP1, MUC9): a differentiation-based mucin present in serum of women with ovarian cancer. Int J Gynecol Cancer 20:16-22

McCombie G, Staab D, Stoeckli M, Knochenmuss R (2005) Spatial and spectral correlations in MALDI mass spectrometry images by clustering and multivariate analysis. Anal Chem 77:6118-6124

Pevsner PH, Melamed J, Remsen T, Kogos A, Francois F, Kessler P, Stern A, Anand S (2009) Mass spectrometry MALDI imaging of colon cancer biomarkers: a new diagnostic paradigm. Biomark Med 3:55-69

Redeby T, Roeraade J, Emmer A (2004) Simple fabrication of a structured matrix-assisted laser desorption/ionization target coating for increased sensitivity in mass spectrometric analysis of membrane proteins. Rapid Commun Mass Spectrom 18: 1161-1166

Redeby T, Carr H, Bjork M, Emmer A (2006) A screening procedure for the solubilization of chloroplast membrane proteins from the marine green macroalga Ulva lactuca using RP-HPLC-MALDIMS. Int J Biol Macromol 39:29-36

Schwamborn K, Krieg RC, Reska M, Jakse G, Knuechel R, Wellmann A (2007) Identifying prostate carcinoma by MALDI-imaging. Int J Mol Med 20:155-159

Schwartz SA, Weil RJ, Johnson MD, Toms SA, Caprioli RM (2004) Protein profiling in brain tumors using mass spectrometry: feasibility of a new technique for the analysis of protein expression. Clin Cancer Res 10:981-987

Seeley EH, Caprioli RM (2008) Imaging mass spectrometry: towards clinical diagnostics. Proteomics Clin Appl 2:1435-1443

Stauber J, Lemaire R, Wisztorski M, Ait-Menguellet S, Lucot JP, Vinatier D, Desmons A, Deschamps M, Proess G, Rudolf I, Salzet M, Fournier I (2006) New developments in MALDI imaging mass spectrometry for pathological proteomic studies: introduction to a novel concept, the specific MALDI imaging. Mol Cell Proteomics 5:S247-S249

Stauber J, Lemaire R, Franck J, Bonnel D, Croix D, Day R, Wisztorski M, Fournier I, Salzet M (2008) MALDI imaging of formalin-fixed paraffin-embedded tissues: application to model animals of Parkinson disease for biomarker hunting. J Proteome Res 7:969-978

Tanner EJ, Black DR, Zivanovic O, Kehoe SM, Dao F, Konner JA, Barakat RR, Lichtman SM, Levine DA (2012) Patterns of first recurrence following adjuvant intraperitoneal chemotherapy for stage IIIC ovarian cancer. Gynecol Oncol 124:59-62

Ushijima K (2010) Treatment for recurrent ovarian cancer-at first relapse. J Oncol 497429

van Remoortere A, van Zeijl RJ, van den Oever N, Franck J, Longuespee R, Wisztorski M, Salzet M, Deelder AM, Fournier I (2010) McDonnell LA MALDI imaging and profiling MS of higher mass proteins from tissue. J Am Soc Mass Spectrom 21:1922-1929 